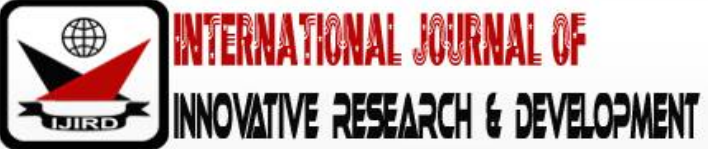

ISSN 2278-0211 (Online)

\section{Road Pavement Failure and Exploratory Analysis of Requirements for Effective Management of Highway Maintenance Projects}

\author{
Moneke Uchenna Ugochi \\ Senior Lecturer, Department of Project Management Technology, \\ Federal University of Technology, Owerri, Nigeria
}

\begin{abstract}
:
Feedback information from investigating causes of Road Pavement Failure (RPF) will provide guidelines for requirements definition and management system for effective delivery of Highway Maintenance Projects (HMP) in Imo State Nigeria. This paper investigates the causes of RPF and explores the requirements needed for effective delivery of HMP to enhance sustainable thoroughfare assets. Expository field surveys with cluster sampling were adopted in the study. A sample size of five dilapidated highways with 78 target respondents and 6 factors in each of the 3 cluster groups of requirements formed the basis for primary data generation. The instrument of data collection and measurement was questionnaire designed in Likert five points scale. The methods of data analysis were the Relative severity index, Kendall's coefficient of concordance and Pearson correlation analysis. The results and findings from the analysis found that poor side drainage system, poor quality of construction design and materials are the severest causes of RPF. The coefficient of concordance $W$ from three raters indicate significant agreement of the three cluster groups of technical, financial and institutional requirements with, $W=70.60 \%, 62.40 \%$ and $61.50 \%$ respectively. Similarly, the result of correlation analysis shows that technical and financial requirements correlate significantly with effectiveness of HMP delivery with coefficients of $69.20 \%$ and $52.40 \%$ respectively. However, institutional requirement through important, did not correlate very strongly in this study. The results suggest that RPF analysis mitigates complexities of figuring out HMP requirements definitions and management system and hence, ensures meeting up with the acceptance criteria, change control and user's satisfaction.
\end{abstract}

Keywords: Financial, highway, institutional, pavement, technical, thoroughfare

\section{Introduction}

The success of highway maintenance project (HMP) may be impaired if the causes of dilapidation are not investigated for action response plan which could be used in articulating requirements definition and follow up management system for effective delivery of thoroughfare assets. Efficient transport system enhances the socio-economic development of a nation. In developing country like Nigeria, the provision and maintenance of effective and efficient transport system is the social responsibility of government. In some cases, partnership becomes viable means of bridging the funding gaps in the road sector. Road infrastructure improvement could catalyze the present rate of growth and development of the economy. However, road pavements are usually challenged which warrants maintenance. The spatial networks of highways in the eastern part of Nigeria are located within the tropical region and rainforest zone characterized by heavy rainfall, extreme geological terrain and environment aggressiveness.

In line with the drive to address the resulting effects on road pavement failure and deterioration, the Federal Road Maintenance Agency (FERMA) was created in 2002 to tackle the challenges of highway maintenance. Road Pavement failure (RPF) analysis provides feedback signals and action response plans for routine or periodic maintenance which keeps the costs low and reduces the need for major rehabilitation projects down the line. According to Elswick (2017), world bank reported that 'roads are among the most important public assets in any country,' so keeping them in good working condition is obviously critical. In addition, effective road maintenance requires regular routine upkeep when major issues occur. Highways are direct public roads especially multilane, high speed thoroughfare for vehicular traffic connecting major population centres. The highways are usually vulnerable to pavement failure especially in the tropical and rainforest zones of the country. Highway Maintenance project (HMP) using inputs from RPF analysis will guide the stakeholders to fix the dilapidated portions through routine or periodic maintenance policies at a budgeted cost with schedules and designed quality specification.

RPF and problems of poor HMP have been the major factors leading to accidents, increasing road user costs, impediment to logistics and decrease in the national economy. There has been incessant deterioration and rapid RPF; with the resulting bloated expenditure and cost overrun exceeding the amount captured in the annual budget for HMP. The rehabilitated and maintained roads lack reliability as they failed to serve intended logistics functions within estimated 
duration. The HMP are usually completed late and shoddily which many of them have been abandoned after committing huge amount of resources. The contracting firms handling the HMP and FERMA have not justified objectively the reasons for the poor performance.

Imo state of Nigeria was created in 1976 with a current population of about 5.2 million people. The three major towns are Owerri; the state capital, Orlu, Okigwe, Oguta, Ikeduru, Mbaise, Ideato etc. It has 15 Federal roads traversing it.The major critical ones link the state capital Owerri and other major cities. These federal highways are in shamble with subjectively more than $70 \%$ portions of the roads in deplorable dilapidation and therefore require effective maintenance to alleviate the suffering of the motorist, commuters and to boost the economic activities of the state. The HMP contracts on these roads awarded by FERMA to some contracting firms failed to meet the expectation of the road users and economic activities. They suffered from shoddy completion, delays, abandonment and eventual failure with colossal waste of resources.

The objectives of the study are therefore to:

- Investigate the causative factors responsible for RPF and dilapidation of federal roads in Imo State so as to assess their respective severity indexes. The result of RPF assessment results will serve as inputs and action response plans in HMP planning and policy formulation for decisive results, efficient and serviceable project delivery.

- To evaluate the requirements for effective HMP so as to minimize the total objective costs while discrete relationship between maintenance time, associated costs and reliability of maintained roads are considered.

- To statistically attest the level of concordance of the opinion of experts on the effectiveness of the salient requirements for HMP of federal roads in Imo State Nigeria.

- To determine the levels of correlation between the salient requirements and effective HMP delivery.

\section{Literature Review: Conceptual Framework}

Pavement failure occurs when an asphalt surface no longer holds its original shape and develops materials stresses which cause issues. Pavement issues include cracking, potholes, depressions, rutting, shoving, upheaval and reveling (Lonestar Paving 2017). According to Kattiparuthi and Koya (2017), cracking of pavement is a defect that appears on the top layer of the road.

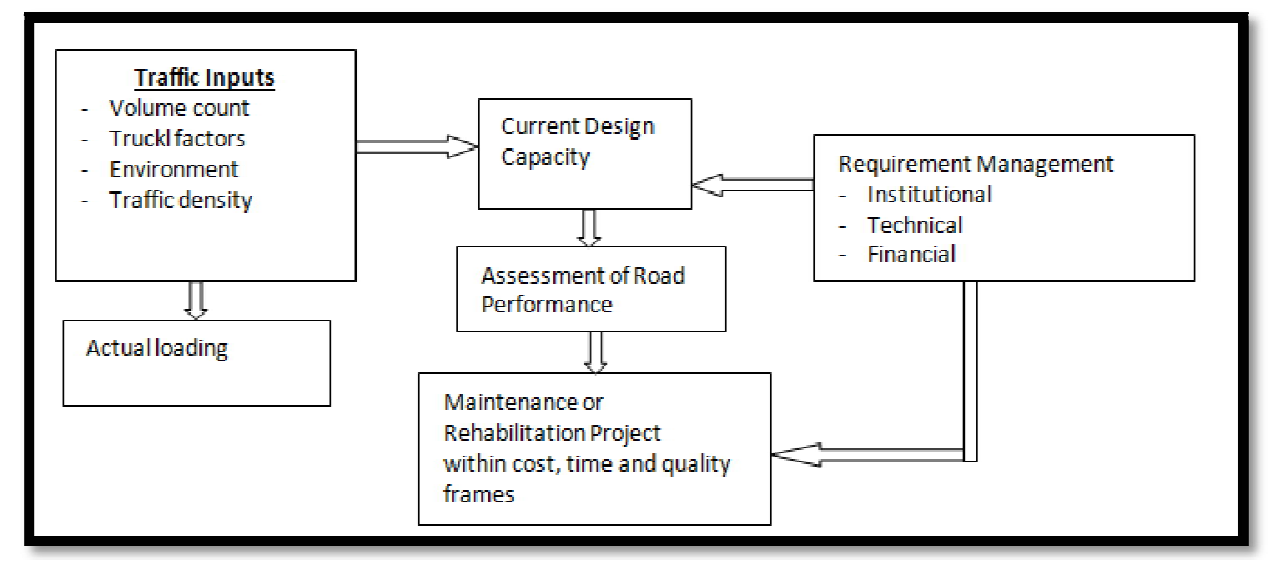

Figure 1: Conceptual Framework for Pavement Failure and Highway Maintenance Project

The pavement deterioration over time is also caused by a combination of several factors such as traffic density, environment, materials and design consideration. The results and findings from the research conducted by Regin et al. (2005), indicate that traffic and the consequent load that vehicles transfer to the roads are major damage to pavements. The intents of their analysis are to assess traffic inputs in determining the needs for road maintenance or rehabilitation.

The maintenance of roads means protecting, restoration and strengthening of all elements of the road to maintain sustainability of the road. Roads are high cost investments and need constant maintenance so that the investments continue to perform as required. Therefore, care must be taken to maintain the roads in optimum and scientific manner (Kattiparuthi and Koya 2017). Prior to going into the maintenance methodologies, Awari (2016) emphasizes that one should consider the reasons for disenchantment of bituminous asphalts. If the maintenance system is weak, road defects will appear and the defects will be the main cause of accidents and the road will be unsafe. The maintenance of asphalts pavements consists of routine and periodic activities. The structural maintenance of the highways specified in this study are considered to be addressed with requirements management.

\subsection{Requirements Management}

Requirement management is the process of documenting, analyzing, tracing, prioritizing and agreeing on requirements and then controlling changes and communication to relevant stakeholders (Coventry 2015). Requirement is a capability to which project outcomes should conform, and is a continuous process throughout a project. According to Coventry (2015), managing requirements is key tool for business and project success .He also posited that studies have shown that requirements management improves all major aspects of organization strategy (portfolio, programs and projects) or operations management (day to day business) by reducing cost, improving quality, decreasing time taken, 
decreasing risks, and enabling effective scope management. According to the CHAOS reports (2004), three of the top five reasons projects fail are related to requirements; i. users are not involved enough in requirement definition ii. requirements are incomplete or don't meet acceptance criteria iii. requirement is constantly changing and these changes are not managed effectively.

Requirements management processes include tasks to; identify stakeholders, gather/elicit, analyze, specify/document requirements, baseline requirement groups (verify, validate, agree and sign-off on requirements), communicate and monitor/ track requirements, manage and control changes to requirements and report requirements compliances. With requirements management,the HMP will assist in preserving the road network, thereby, avoiding needs for costly rehabilitation or reconstruction at a later date and to improve the efficiency of road maintenance program for the future. Also, the introduction of cost benefit analysis techniques and new research into Imo state highway maintenance planning will make its operations more efficient, promoting the development of competitive road construction industry and road maintenance as core values. France-Mensah (2017) posits the factors affecting HMP and RPF as; traffic intensity, thickness of pavement and number of lanes. The findings of the research conducted by Jy Chein and Tang (2008) on; Scheduling Work Zones for Highway Maintenance Projects, considering a discrete time - cost relationship;infers that highway maintenance usually requires lane closures and disrupts traffic operations, and hence increasing pressure to reduce construction time and alleviate the traffic impact. However, accelerated construction and compressed schedules are expensive and could lead to shoddy work and low-quality delivery. According to Jamal (2017), maintenance of highways preserves and keeps each type of roadway and roadside structures as near as possible in its original conditions as constructed or as subsequently improved upon. Also, the operations of highway facilities provide satisfactory and safe transportation services. The components of highway maintenance include; surface maintenance, roadside and drainage, shoulder and approach, traffic services, bridge maintenance, snow and ice control (Jamal 2017).

\subsection{Theoretical Framework}

Pavement can be under compression and tension at the same time, but in different directions. While a tire compresses a pavement downwards, it forms a deflection basin which causes the pavement to go into tension in both horizontal directions. Kattiparuthi and Koya (2017) postulate that if the pavement is not strong enough, the asphalt is stretched too far, which separates, and a crack forms in the wheel tracks or between the wheel tracks. Arif and Bayraktar (2012) postulate that theoretical framework on transportation infrastructure assets management focuses on planning, contractual arrangement and mechanism; monitoring and performance measurement, information system and decisionmaking. These are well predisposed to maintenance project management of highway infrastructures.

Fuzzy set theory and geographical information system (GIS) are also considered in HMP. Fuzzy set theory among other was developed for determining the best type of maintenance period length and replacement time. The decision of replacement is based on cost consideration while the maintenance type is based on the maintenance factors (Chaudhure and Suresh 1995). Selecting optional maintenance strategy under fuzzy environment is not a trivial task. Verma Srividya, Rajesh, Gaonkar (2007) presented an illustration of multi-criteria maintenance strategy selection under fuzzy environment. A Geographic Information System (GIS) theory is a system designed to capture, store, manipulate, analyse, manage and present all types of geographical data in other words, data that is in some way referred to location on earth. GIS can be used to demonstrate the spatial temporal representation of project data and can lead to early identification of potential overlaps during the highway maintenance planning phase. According to France-Mensah, Brien, Khwaja and Bussel (2017) in a broader context, such geospatial visualization effects provides knowledge inputs in the development of spatial decision support systemsto address planning challenges of a typical highway agency.

The study conducted by Sally and Natalyo (2006) on; 'Why Road Maintenance is Important and How to Get it Done' highlighted the economic and social importance of regular road maintenance and recommended ways to achieve sustainable road maintenance with scarce public resource. They found that roads, and other means of transport, make a crucial contribution to economic development and growth; and also bring important social benefits. They affirm that poorly maintained roads constrain mobility, significantly raise vehicle operating costs, increase accident rates and their associated human property costs. They also aggravate isolation, poverty, poor health and illiteracy in rural communities. Maintenance and repairs of roads must be planned for rapid performance and to cause least possible disruptions or hazards to traffic.

\subsection{Requirements for Effective Highway Maintenance}

Large portion of a country's resources are devoted to highway development; delaying in some cases, investments in other sectors as usually captured in the capital annual budgets. Ball (1992) asserts that for these and other reasons, government rely on skill professionals to provide expert planning and engineering counsel to ensure successful highway projects. But the success of investment in highways depends on more than planning and engineering services. Ball (1992) avers that technical assistance in maintaining the constructed highways is critical for ensuring that the economic benefits of highway are realized. Requirement management helps suppliers and customers to understand and agree on what is needed and to avoid wasting time, resources and efforts; and helps ensure project success by avoiding the top reasons for project failure such aspoor requirements capture, scope creep, disagreements about acceptance (Ball 2015).According to CDC Template (2019), requirement plan is used to document the necessary information required to effectively manage project requirements from definition, through traceability, to delivery.

Requirement is technically and operationally possible to do within the existing constraints; for instances of typical time and money. Efforts are spent during design and implementation trying to figure out what the requirements are. Poor requirements cause the wrong products to be delivered or descoping to meet schedule and cost constraints, (Ludwing 
2006). He also avers that requirements quality affects work performed in subsequent phases of the system life cycle. This could be the reason why the research conducted by Yang et al. (2014) inferred that training and continuous improvement are critical to requirement definition and management. Increased maintenance effort and lack of traceability increases the effort to identify where changes are required especially as knowledgeable personnel leave. Poor management of requirements in addition creates disputes with the customer/clients. It creates ambiguity which causes difference in expectations and contractual issues. They are among the major causes of project failure as adduced by Ludwing (2006).

The salient requirements for effective HMP as postulated by authors are:

\subsubsection{Institutional}

Establishing competitive environment according to Ralph (2001), increases specificity, improving organizational effectiveness and efficiency but also introduces competitive elements for the interested parties. The aim of competition should be to gain work of sufficient quality at the most economic price. Competition can be based on price, quality, performance or the mixture of the three. However, the introduction of competition and business-oriented objectives into a public organization requires a change in culture and the implications can be threatening to existing civil or public workers. According to Lekovic and Cvetanovic (2012), institutional environment is determined by the legal and administration framework within which individuals, business and government interact in order to stimulate production and raise the citizen's standard of living. The importance of institutional environment is in improving competitiveness.

\subsubsection{Technical}

According to Ball (1992), technical assistance in maintaining constructed highways is critical for ensuring that the economic benefits of highways are realized. The success of investment on HMP depends on more than planning and engineering services. Range of techniques used is dependent on the nature of the deterioration, which comprises of anything from minor potholes or surface patches. Universal pavement construction and drainage upgrades are also included depending on the source of the damage (Ralph, 2001).

\subsubsection{Financial}

In order to achieve the objectives of the road maintenance projects and agency activities, large funds are required. As a consequence, most agencies are now trying to improve the efficiency of their maintenance plans by adopting several new strategies. The main target of these newer strategies is accomplishing a possible maintenance at the least possible cost. Some of these strategies include: maintenance contracting methods, improving the management of the available resources, standardizing and improving production process, prioritizing of the work activities and implementation of new technologies. Despite the importance of roads in terms of both their intrinsic value and the role they fulfill, most of them are poorly managed and badly maintained in the developing world. It is estimated that in subSaharan Africa alone, it will be in the range of $\$ 40$ billion to repair all the roads requiring immediate rehabilitation and reconstruction. Funds for road maintenance in Nigeria had been from Federal government allocation to the Federal ministry of work and housing, as well as state and local government allocation for maintenance purpose (Central Bank of Nigeria 2009).

The literature review identified the following causative factors of RPF as opined by Rejin et al (2005). Tarawneh and Sarireh (2013) Okigbo (2012) and France-Mensah (2017) include; effects of cracks and structural failure, standards/specification policy, traffic load and volume, material properties, contraction conditions, drainage system and underground water, alignment and geometry of roads, flexible pavement, layer thickness, pavement with high maintenance, poor design and construction poor maintenance of already/existing built highways, low quality materials in construction, poor workmanship, poor supervision of construction works, heavy traffic not meant for the road, poor highways facilities, no knowledge based, inadequate sanction for highways failures, no local standard of practice, poor laboratory insitu test on soil and week local professional bodies in highway design, shoddy construction and management, traffic intensity, number of lanes, thickness of pavements. Some of these factors from different authorities share similarities with each other and therefore summarized for RSI analysis. Also, the identified requirements for HMP are institutional, technical and financial requirements. There is a gap of exploring the potentials of requirements management system for sustainable HMP delivery.

\section{Methodology}

Given the theoretical review presented in this study, the causative factors for RPF and requirements for effective HMP in Imo State Nigeria could be described as agents of deterioration and hence, the needs for managing requirements for decisive remedies so as to ensure operative sustainable roads. A field survey research design was adopted with cluster sampling on the five federal highways linking the state capital of Imo State Nigeria. A sample of three clusters of hypothesized requirements with their respective construct factors and seventy-eight target respondents were used for the study. The highways are;

\section{$\mathrm{R}_{1}$ : $\quad$ Owerri - $\quad$ Umuahia road $(63 \mathrm{~km})$ Route 417}

$\mathrm{R}_{2}: \quad$ Owerri - $\quad$ Umanelu - Port-Harcourt Road (36 km) Route 414

$\mathrm{R}_{3}$ : $\quad$ Owerri - $\quad$ Aba road $(36 \mathrm{~km})$ route $25 \mathrm{~A}$

$\mathrm{R}_{4}: \quad$ Owerri - $\quad$ Orlu road $(36 \mathrm{~km})$ route 414

$\mathrm{R}_{5}$ : $\quad$ Owerri - $\quad$ Onitsha road $(70 \mathrm{~km})$ route $25 \mathrm{~B}$

Estimated $70 \%$ of portions of these highways are either seriously dilapidated, shoddily completed, abandoned or have failed under FERMA supervision. The primary data used for the study were generated through the instrument of 
questionnaire designed in Liker five-point scale. The population size of the target respondents was (100) small and therefore used as sample size. The target respondents are the experts who are conversant with the state of highways in the state. Three groups of respondents were used as shown below; Civil Engineers (CE), Quantity Surveyors (QS) and Maintenance Project Managers (MPM). These are skilled experts and professionals in HMP from whom their opinions and perceptions were elucidated based on scoring model ranging from; strongly disagree $=1$ point, to strongly agree $=5$ points scores on the factors of RPF and requirements for effective HMP.

The five highways for maintenance project span through the three geopolitical zones of Imo State; Owerri (OW), Okigwe (OK) and Orlu (OR). The copies of questionnaires were distributed based on the population density of experts and target respondents; and the number of dilapidated highways from these zones. These experts are conversant with HMP and have many years of practical working experiences in the field. A total of 100 copies of questionnaire were distributed by zone and by profession of the target respondents with the highest number allocated to OW zone being the state capital.

\begin{tabular}{|c|c|c|c|c|}
\hline \multirow{2}{*}{ Zone } & Profession & \multicolumn{3}{|c|}{ Number of Questionnaire } \\
\cline { 3 - 5 } & of Experts & Distributed & Returned & \% Returned \\
\hline \multirow{2}{*}{ OW } & CE & 17 & 14 & 82.35 \\
& QS & 13 & 10 & 76.92 \\
& MPM & 10 & 8 & 80.00 \\
\hline & Total & 40 & 38 & 80.00 \\
\hline OK & CE & 10 & 6 & 60.00 \\
& QS & 13 & 7 & 53.85 \\
& MPM & 7 & 5 & 71.43 \\
\hline OR & Total & 30 & 18 & 60.00 \\
& CE & 12 & 11 & 91.67 \\
& QS & 10 & 9 & 90.00 \\
& MPM & 8 & 8 & 100.00 \\
\hline & Total & 30 & 28 & 93.33 \\
\hline
\end{tabular}

Table 1: Questionnaire Distribution and Return by Zone and Professional Expert

A total of 78 copies of questionnaire was returned out of 100 copies distributed to the target respondent; representing $78 \%$.

The highest number of questionnaires returned came from OW zone, being the state capital, followed by OR zone, which has the highest number of local government councils. The OW and OR zones have many dilapidated, uncompleted and on-going HMP under the supervision of FERMA. OK zone has least number of questionnaires returned. It has the least number of local government councils and the least in terms of roads infrastructure development. From table 1 , numbers of target respondents that completed and returned the questionnaire are: $\mathrm{CE}=31, \mathrm{QS}=26$, and $\mathrm{MPM}=21$.

\subsection{Methods of Data Analysis}

The study adopted three methods of data analysis;

- $\quad$ Relative Severity Index (RSI); for investigating causative factors of RPF, and dilapidation.

- Kendall's coefficient of concordance; for determining the level of agreements between the three groups of rankers of the three requirements and their 18 construct factors.

- $\quad$ Correlation analysis; for determining the level of influence or correlation coefficient r; the requirements factors have with effective delivery of HMP. The effectiveness for HMP parameters is; within budgeted cost, schedule, quality specification and reliability, environmental sustainability, within scope and risk containment.

\subsection{Relative Severity Index Analysis}

RSI was used to ascertain the degree RPF and the result provided action response plan for effective HMP.

$\mathrm{RSI}=\sum_{i}^{n} \frac{w i f i}{w} \times \frac{100}{1}$ equation 1

where $\mathrm{W}_{\mathrm{i}}=$ weighted score of individual factors, $\mathrm{W}=$ maximum weighted score.

Agreement in ranking and Kendall's coefficient of concordance:

Kendall's coefficient of concordance for ranks (W) was used to calculate agreements between the three groups of the rankers of the 18 factors being considered in 3 cluster groups. The rankers are 31 CE, 26 QS and 21 MPM, totaling 78. Kendall's coefficient of concordance: $\mathrm{W}=\frac{12 s^{2}-3 p^{2} n(n-1)^{2}}{p^{2}\left(n^{3}-n\right)-p T} \ldots . .$. equation 2

where $\mathrm{S}=\sum R^{2}=$ sum of square statistics over the row of ranks $\mathrm{R}_{\mathrm{i}}, \mathrm{P}=$ number of group of rankers which is 3 in this case, $\mathrm{T}$ $=$ correlation factor required for tied ranks $n=$ number of required factors considered as decisive for effective HMP, which is 18 in cluster groups of 3 salient requirements for HMP.

The Friedman's $\mathrm{X}^{2}$ statistic is usually used to test Kendall's coefficient of concordance W for statistical significance. According to AKanni, Oke and Akpomiemie(2014), Chi-square and probability are not calculated in the usual way when sample size of judges is small i.e. $\mathrm{P} \leq 7$; instead direct probability is obtained from table of critical values. The tests were conducted at 95\% confidence interval.However, the computation of $\mathrm{W}$ and coefficient of correlation were done 
with computer software; Statistical Program for Social Science (SPSS), version 21. The SPSS generated the results used for discussion, inferential confirmation and conclusion.

\section{Data Presentation and Analysis}

\begin{tabular}{|c|c|c|c|c|c|c|c|c|c|}
\hline \multirow{2}{*}{ code } & \multirow{2}{*}{ Causative factors of RPF } & \multicolumn{5}{|c|}{ Frequency } & \multirow{2}{*}{$\begin{array}{l}\text { Total } \\
\text { score } \\
\sum{ }^{\prime} w_{i f i}\end{array}$} & \multirow{2}{*}{$\begin{array}{l}\text { RSI } \\
(\%)\end{array}$} & \multirow{2}{*}{ Rank } \\
\hline & & SD & $\mathrm{D}$ & $\mathrm{N}$ & A & SA & & & \\
\hline 51 & Cracks and structural defects & 8 & 10 & 22 & 18 & 20 & 266 & 59.11 & $5^{51}$ \\
\hline 52 & Standards/specifications policies abuse & 8 & 20 & 14 & 18 & 18 & 252 & 56.00 & $7^{70}$ \\
\hline 53 & Traffic and loaddensities & 8 & 26 & 10 & 14 & 20 & 246 & 54.67 & $g^{n}$ \\
\hline 54 & Construction conditions and soil texture & 28 & 18 & 15 & 10 & 7 & 184 & 40.89 & $15^{n}$ \\
\hline 55 & $\begin{array}{l}\text { Poor drainage systems and underground water } \\
\text { discharge }\end{array}$ & 2 & 8 & 8 & 20 & 40 & 322 & 71.56 & $1^{\text {st }}$ \\
\hline 56 & Alignment and geometry of roads & 22 & 18 & 18 & 10 & 10 & 202 & 44.89 & $13^{\pi}$ \\
\hline 57 & Inadequate number of lanes & 31 & 19 & 14 & 6 & 8 & 175 & 38.89 & $16^{\mathrm{n}}$ \\
\hline 58 & Thin layer thickness & 10 & 8 & 8 & 24 & 26 & 276 & 61.33 & $4^{2 n}$ \\
\hline 59 & Poor design and construction & 3 & 5 & 10 & 24 & 36 & 319 & 70.89 & $2^{\text {no }}$ \\
\hline 510 & Lack of effective maintenance culture & 17 & 20 & 18 & 8 & 14 & 213 & 47.33 & $12^{2 n}$ \\
\hline 511 & Low quality materials & 2 & 6 & 18 & 22 & 30 & 306 & 68.00 & $3^{\text {ro }}$ \\
\hline 512 & Topography and geological terrain & 10 & 8 & 14 & 26 & 20 & 252 & 56.00 & $7^{7}$ \\
\hline 513 & Poor highways facilities & 30 & 18 & 12 & 8 & 10 & 184 & 40.89 & $14^{2}$ \\
\hline 514 & No knowledge basedin maintenance & 9 & 10 & 20 & 20 & 19 & 264 & 58.67 & $6^{n}$ \\
\hline 515 & Inadequate sanction for highway offenders & 44 & 15 & 10 & 3 & 6 & 146 & 32.44 & $17^{\circ}$ \\
\hline 516 & Poor laboratory insitu test & 16 & 22 & 8 & 18 & 14 & 226 & 50.22 & $11^{\text {th }}$ \\
\hline 517 & Weak local professional bodies & 50 & 15 & 7 & 5 & 1 & 126 & 28.00 & $18^{27}$ \\
\hline 518 & Poor workmanship and supervision & 18 & 10 & 10 & 24 & 16 & 244 & 54.22 & $10^{2}$ \\
\hline
\end{tabular}

Table 2: Analysis for Relative Severity Index of RPF and the Results

\begin{tabular}{|c|c|c|c|}
\hline & \multicolumn{3}{|c|}{ Mean Ranks from Raters: } \\
\hline Clusters of Requirements. & CE. & QS & MPM \\
\hline \multicolumn{4}{|l|}{ Institutional } \\
\hline F1: Drive for competition & 11.67 & 11.82 & 12.16 \\
\hline F2: Planning and regulatory functions & 7.13 & 8.19 & 7.48 \\
\hline F3: Terms and conditions of contract & 13.95 & 13.16 & 13.4 \\
\hline $\begin{array}{c}\text { F4: Changes in government or } \\
\text { contractors }\end{array}$ & 13.33 & 13.13 & 13.06 \\
\hline $\begin{array}{c}\text { F5: Extant legal and administrative } \\
\text { framework }\end{array}$ & 9.83 & 8.31 & 9.12 \\
\hline $\begin{array}{l}\text { F6: Changes in public organization and } \\
\text { culture. }\end{array}$ & 12.24 & 11.6 & 11.73 \\
\hline \multicolumn{4}{|l|}{ Technical } \\
\hline $\begin{array}{c}\text { F7: Availability of machines and } \\
\text { equipment }\end{array}$ & 5.52 & 4.9 & 5.29 \\
\hline F8: Quality of design and scope definition & 5.4 & 6.68 & 6.19 \\
\hline $\begin{array}{l}\text { F9: Skills and dexterity of maintenance } \\
\text { crew }\end{array}$ & 4.86 & 4.89 & 4.56 \\
\hline F10: Adequate engineering services & 5.76 & 6.19 & 6 \\
\hline $\begin{array}{c}\text { F11: Availability of spare parts for } \\
\text { machines and equipment }\end{array}$ & 11.62 & 11.56 & 11.65 \\
\hline F12: Quality materials and timely delivery & 10.76 & 11.18 & 10.98 \\
\hline \multicolumn{4}{|l|}{ Financial } \\
\hline F13: Budget provision for HMP & 8.52 & 9.31 & 9.1 \\
\hline F14: Inflation control & 12.12 & 12.13 & 12.46 \\
\hline F15: Exchange rate control & 11.19 & 11.39 & 11.33 \\
\hline $\begin{array}{l}\text { F16: Cost breakdown structure and } \\
\text { control }\end{array}$ & 5.14 & 4.98 & 5.23 \\
\hline F17: Funding options & 13.1 & 11.89 & 12.13 \\
\hline F18: Payment pattern and mobilization & 8.81 & 9.24 & 9.19 \\
\hline
\end{tabular}

Table 3: Three Clusters of Requirements with Mean Ranks of Eighteen Factors for HMP

Source: SPSS Result Outputs 


\begin{tabular}{|c|c|c|c|c|c|c|}
\hline Requirement & W & $\begin{array}{c}\text { Chi-square } \\
\boldsymbol{x}^{\mathbf{2}}\end{array}$ & df & $\begin{array}{c}\text { Asymp } \\
\text { sig. }\end{array}$ & Rank & Remarks \\
\hline Institutional & 0.615 & 128.21 & 17 & 0.000 & $3^{\text {rd }}$ & Significant \\
\hline Technical & 0.706 & 161.24 & 17 & 0.000 & $1^{\text {st }}$ & Significant \\
\hline Financial & 0.624 & 143.38 & 17 & 0.000 & $2^{\text {nd }}$ & Significant \\
\hline
\end{tabular}

Table 4: Result of Kendall's Test of Concordance $W$ for Each of the

Requirement and Test of Significance

Source: SPSS Results Outputs

\begin{tabular}{|c|c|c|c|c|}
\hline Requirement & $\begin{array}{c}\text { Correlation } \\
\text { coefficient }\end{array}$ & P-value & Rank & Remarks \\
\hline Institutional & 0.392 & 0.226 & $3^{\text {rd }}$ & Not significant \\
\hline Technical & 0.692 & 0 & $1^{\text {st }}$ & significant \\
\hline Financial & 0.524 & 0.014 & $2^{\text {nd }}$ & significant \\
\hline
\end{tabular}

Table 5: Pearson Correlation Analysis Results of the 3 Clusters of

Requirements and Effectiveness of Hmp Delivery

Source: Excerpt of Spss Result Outputs

\section{Discussion of Result and Findings}

This study has examined and conducted quantitative analysis of the causative factors of RPF and requirements for management of HMP in Imo state Nigeria. A total of 18 factors of RPF and 3 salient requirements for the maintenance projects were identified vis-a-vis: technical, financial and institutional requirements. All the three salient requirements for effective HMP are found to be in agreement with the three rankers, and two out of three of them correlate significantly with the effectiveness of HMP.

The results and findings from RSI analysis infer that the three severest causes of RPF and dilapidation are; poor or lack of side drainage system, poor quality of construction design and low quality and quantity of maintenance materials .The nature of the geographical zone, topography and geological terrain require decisive strategies in terms of resources and skills to achieve sustainable HMP delivery.

The technical requirements are made in accordance with the project concepts and scope. Usually the project concept is loosely based on the client's vision of the projects and includes the goals and purposes of the products to be built, its high level design, the suggested technology stack and rough estimation .When the project concept is completed and approved by the client; it becomes the basis for the technical requirements. The document of technical requirements is a detailed list of all features and functions with the required technologies. The result of the analysis infers that technical requirements rank first in agreement for effective delivery of HMP with $\mathrm{W}=0.706$ and $\mathrm{r}=0.692$.According to Wrike (2019), technical requirements are the technical issues that must be considered to successfully complete the projects. These are aspects such as performance, reliability and availability that must be met in order to proceed with a project. Asian Development Bank (ADB 1957) attests that the required financial and technical requirements availability initiated a pilot road maintenance project in the Sidney. Through technical requirements, design process and costs are assessed which are key inputs to the commercial feasibility analysis. Technical competences for HMP are usually provided by Civil Engineers who perform engineering duties in planning, designing and overseeing construction and maintenance of building structures and facilities, such as roads, railroad, airports, etc., Mymajor (2018). However, Jasoren (2019) reports that it is only when technical requirements are approved by the client that the development begins.

Financial requirements rank second with $\mathrm{W}=0.624$ and $\mathrm{r}=0.524$ in the level of concordance and correlation respectively from the result of analysis. Funding is required at each stage in the HMP life cycle and as the activities develop, emergent maintenance works require financing as well. Financial requirements are actual or projected sum of money required to execute a plan, project or program. Analysis to ascertain the financial requirements for HMP are indispensable for project success. The findings and results from the research conducted by the Word Bank (2009) concurred that the poor state of national highway system in Ecuador is in a very poor condition stemming from improper maintenance and construction due to lack of funds, inadequate equipment and ineffective maintenance organization. The research conducted by Volovski (2020) on, 'funding for highway asset construction and maintenance: sustainable alternatives to the traditional gas tax' indicates that the funding need for highway construction, rehabilitation, maintenance and operations are obtained from various highway revenue sources. Volovski (2020) also avers that government must decide on the goals of the efforts, authorities for setting fees and controlling revenue, the basis for determining fees and how best to involve private sector. In Nigeria, it could be necessary for private sectors to be involved in funding of HMP to augment government efforts in providing the needed financial requirements for routine maintenance.

FERMA is the main institution charged with the regulation, monitoring and evaluation of HMP in Nigeria, but allegedly without significant influence. Institutional framework is the precondition for successful implementation and an important process for preparing the ground for sustainable HMP. Institutional requirements rank third with W=0.615 and $r=0.392$ in the concordance rating and correlation analysis respectively. The framework in this case could be linked to a law, or other formal provision that assign primary responsibility as well as the authority to an agency for the collection, processing and dissemination of the statistics to certain specific sectors. It also includes arrangements or procedures to facilitate sharing and coordination between data. According to Miller, Drovin and Sankara (2016), institutional theory 
suggests that institutions (or organizations) possess structures, stability and meaning for people's social behavior in the organization.

\section{Conclusion}

Results and findings from RPF will be considered in decision making for containment of dilapidation and action response plan for HMP requirements definition and follow up management of changes by the stakeholders. Management of requirements will help to accomplish the HMP within schedule budgeted cost, quality, reliability and environmental sustainability. In addition, it is a key to preserving strength and quality as well as keeping the cost of maintenance low. The analysis of RSI on the 18 identified causative factors of highway dilapidation was carried-out. Poor or lack of side drainage system, poor quality of design and materials were inferred to be severest causes of dilapidation and need to be taken into consideration during requirements and scope definition and work breakdown structure. Also 3 salient requirements for HMP were identified, and subjected to Kendall's coefficient of concordance analysis by three rankers. The result yielded a significant level of agreement on the three requirements with their 18 factors presented in a prioritized ranking order of technical, financial and institutional clusters. The results of correlation analysis indicate that technical and financial requirements correlate strongly with the effectiveness parameters of HMP: while that of institutional did not indicate significant correlation; which could be due to its public sector affiliation. The study has investigated and explored RPF and effective implementation of HMP respectively and examined how stakeholders (CE, QS and MPM) responded and agreed on the requirements definition and management. Also, their inferential correlations with sustainable thoroughfare asset development were reported. The results and findings from the study will present decision guidelines for requirements management through the enabling processes for effective HMP delivery.

\section{References}

i. Akanni P.O., Oke O.E. and Akpomiemie O.A (2014) Impact of Environmental Factors on Building Project Performance in Delta State Nigeria Housing and Building National Research Centres HBRC Journalhttp://ces.elsevier.com/hbrc.

ii. Arif F. and Bayraktar M.E. (2012) Theoretical Framework for Transportation Infrastructure asset Management Based on Review of Best Practices. Construction Research Congress (2012) @ ASCE 2012, http:/www.rechargeget..com

iii. Asian Development Bank (1957) Guide to Performance-Based Road Maintenance Contracts. CARE Program ADB.

iv. Awari M.B. (2016) Flexible Pavement Deterioration and Solution. VSRD. International Journal of Journal of Mechanical, Civil, Automobile and Production Engineering. Vol.vi Issue x.www.vsrdjournals.com.

v. Ball J.R. (1992) Highway Maintenance Management. Transportation Research board. http://trid.trb.org/view/3.

vi. Bell M. (2015) Requirement Management. APM Chartered Body Project Management Professional. http://www.2a.cdc.gov>template.

vii. Brilakis I. (2019) Why Road Maintenance is Important and How to Get it done MIDWEST http://www.blogmidwest.com.

viii. CDC Template (2019) Requirement Management Plan. CDC Templatehttp://www.2a.cdc.gov>template.

ix. Chaudhure D. and Suresh P.V. (1995). An Algorithm for Maintenance and Replacement Policy Using Fuzzy Set Theory. Reliability Engineering and Safety System. Vol.50, Issue I Coventry (2015) Requirement Management Planning for Success. Techniques to Get it Right When Planning Requirement. http://www.pmi.org.

x. CHAOS Report (2004) The Standish Group International Incorporation. Elswick F (2017) Why Road Maintenance is Important and How to Get it Done in Gravel Roads, Green paved, unpaved Roads Midwest's (Road Consultancy) Industrial Supply.

xi. $\quad$ France-Mensah J, Brien P.K., kwaja S.E > and Bussal P (2017) Geographical Integrated Highway Maintenance and Construction Planning. A Case Study of Forth Worth Texas. Springer Visualization in Engineering.

xii. Gaonkar et al. (2008) Exploring Fuzzy Set Concept in Priority Theory for Maintenance Strategy Selection Problem http://www.researchgate.net.

xiii. Jamal H. (2017) Road Maintenance, Highway Maintenance Transportation Engineering. http://www.aboutcivil.orgmtcofhwsrdhtml

xiv. Jasoren (2019) Importance of Technical Requirements http://jasoren.com.

xv. Kattiparuthi R.A. and Koya A.M. (2017) Theoretical Framework; Evaluation of Flexible Pavement Failure; A Case Study on Izki Road International Journal of Advanced Engineering Management and science (IJAEMS) Vol.3, Issue 7, Iss $2454-13111$

xvi. Lekovic V and Cvetanovic C. (2012) Institution as a Factor of Competitiveness Improvement in Managing Structural Changes. Trends and Requirements http://ideas.repec.org.

xvii. Lonestar Paving (2017) What is Pavement Failure. http://www.lonestarpaving-tx.com

xviii. Ludwing Consulting Services (2006) Managing Requirements www.jiludwing.com.

xix. Mymajors (2019) Highway Engineering Career. http://www.mymajors.com

xx. Muller R. Drouin N. and Sankara S. (2016) Institutional Theory and Organizational Project Management. Theory and Implementation. Elgar Introduction to project Management and Organizational Theory Serieshttp://www elgarline.com

xxi. $\quad$ Okigbo N. (2012) Causes of Highway Failure in Nigeria. Vol. 4(ii) $4695-4703$. 
xxii. Ononuju C.N. and Moneke U.U. (2016) Critical Factors and Decision Variables Affecting Quality and Reliability in Road construction projects in Nigeria International Journal of Advanced Research (IJAR)

xxiii. Ralph H. (2001) Reinventing the Pavement Wheel. Fifth Edition International Conference on Managing Pavement.

xxiv. Regain J, Regidor F Romeo A.I.I and Bilugan V. (2005) Assessment of Traffic Inputs to pavement Design and Rehabilitation. Philippines Engineering Journal Vol.5. No. 2; 1 - 12. http://www.researchgate.net.

xxv. Sally B and Natalya S. (2005) Why Road Maintenance is Important and How to Get it Done. World Bank Other Operational Studies E 11779 http://ideas.repec.org.

xxvi. Tang Y, and Jy Chein S. (2008) Scheduling Work Zones for Highway Maintenance Projects; Considering a discrete Time-cost relation. Journal ofthe Transport Research Board. http://doi/10.3141/205503,http://www.journal.sagepub.com

xxvii. Tarawneh S. and Sarireh M. (2013). Causes of Cracks and Deterioration of Pavement on Highways in Jordan From Contractors Perspective. Vol.3(10) Pp16-27.

xxviii. Verma A.K, Srividya A. and Prabhu R.S. (2017) Fuzzy Set Solutions for Optimal Maintenance Strategy Selection. Springer Link Technical Note. Vol. 44, Issue 3 Pp 261 - 276.

xxix. Volovski M. (2020) Funding for Highway Asset Construction and Maintenance: Sustainable Alternatives tothe Traditional Gas Tax; mvolovski@ Purdue.edu.

xxx. World Bank Report (2009) Highway Maintenance and Construction Projects. http://project.worldbank.

xxxi. Wrike (2019) What are Technical Requirements in Project Management. Advanced Terminology http://www.wrike.com.

xxxii. Yang L, Chen J, and Wang X (2015) Assessing the Effect of Requirement Definition and Management on Performance Outcomes: Role of Interpersonal Conflict, Product Advantage and Product Structure. International Journal of Project Management (33) 2015 67-80. Elsevier. www.Elsevier.com/locate/ yproman. 